\title{
Adsorption Behavior of Hydroquinone by Diatomite-based Porous Ceramsite
}

\author{
Ruqin Gao*, Lu Pan*, Yingrui Huang*, Zhaoyang Wu**† and Bingtao Liu* \\ *School of Environmental and Municipal Engineering, North China University of Water Resources and Electric Power, \\ Zhengzhou 450046, China \\ ** Zhengzhou Institute of Multipurpose Utilization of Mineral Resources, CAGS, Zhengzhou 450006, China \\ †Corresponding author: Zhaoyang Wu; wzy500@sina.com
}

Nat. Env. \& Poll. Tech.

Website: www.neptjournal.com

Received: 16-07-2020

Revised: $13-12-2020$

Accepted: 26-05-2021

\section{Key Words:}

Diatomite-based porous

ceramsite

Hydroquinone

Adsorption kinetics

Moving-boundary model

Liquid film diffusion

\section{ABSTRACT}

Diatomite-based porous ceramsite is a new kind of environmental material. In this study, ceramsite was prepared by wet grinding, a rolling-ball method, and high temperature-calcination using diatomite as the main raw material with the addition of a pore-forming agent and sintering assistant. X-ray diffraction, scanning electron microscopy, and mercury injection, were used to analyze the structure and characteristics of the prepared materials. Using hydroquinone as the target pollutant, the adsorption behavior of diatomite-based porous ceramsite was investigated. Results indicated that the diatomitebased porous ceramsite had a pore size ranging from 500 to $3000 \mathrm{~nm}$, a specific surface area of 6.14 $\mathrm{m}^{2} \cdot \mathrm{g}^{-1}$, and a porosity of $47.8 \%$. When $\mathrm{pH}$ was 7 , the removal rate and adsorption capacity of the hydroquinone by the diatomite-based porous ceramsite was $91.2 \%$ and $4.56 \mathrm{~m}^{2} \cdot \mathrm{g}^{-1}$, respectively. In the adsorption process of hydroquinone by diatomite-based porous ceramsite, the diffusion of a liquid membrane was dominant, which could be better described by the quasi-first-order kinetic equation. The Langmuir and Koble-Corrigan equations had a higher fitting degree of data for the adsorption isotherms. The adsorption characteristics of the diatomite-based porous ceramsite are in accordance with the fixed-point adsorption of a single molecular layer and belong to a heterogeneous composite adsorption system. The correlation coefficient $\mathrm{R}^{2}$ and $\mathrm{k}$ value of hydroquinone adsorption by the diatomite-based porous ceramsite determined by the liquid film diffusion model were 0.848 and 0.0417 , respectively.

\section{INTRODUCTION}

Diatomite is unicellular algal debris that is deposited in the ocean or lakes and can form diatomite. Diatomite is a non-metallic porous mineral that has a small density, a large specific surface area, good adsorption properties, is chemically stable, and has pores with the size of $50-800 \mathrm{~nm}$ (Iuchaurroudo et al. 2016, Zahra et al. 2018, Tan et al. 2018, Font et al. 2018). Hydroquinone is an important chemical raw material and chemically synthesized intermediate that is widely used in photographic developer, antioxidants, and synthetic ammonia co-solvents in rubber. Hydroquinone is an important organic pollutant that is highly toxic and difficult to degrade. It can be easily oxidized into benzoquinone which is more toxic to the central nervous system and liver in humans. It is also one of the main pollutants in industrial wastewater which can cause great harm to organisms and the environment (Ergürhan et al. 2018, Yıldız et al. 2005, Xu et al. 2019, Li et al. 2013).

Ceramsite is a new type of porous material that has a small bulk density, high porosity, good chemical and thermal stability, can be easily regenerated at low cost with good mechanical strength. Ceramsite can be made of clay, sludge, or fly ash that is mixed with sintering aids and pore-forming agents. These are ground, balled, and calcined at high temperature, and are widely used in construction materials, sewage treatments, the petrochemical industry, and gardening (Chen et al. 2010, Qin et al. 2015, Che et al. 2018, Li et al. 2019, Wang et al. 2019a, Wu et al. 2016, Podder \& Majumder 2016). In this study, diatomite-based porous ceramsite was prepared and its adsorption effect on hydroquinone was elucidated. The results provide a theoretical basis for exploring the efficient utilization of diatomite, the optimal allocation of resources, and the sustainable development of the environment.

\section{MATERIALS AND METHODS}

\section{Material and Reagent}

Diatomite was produced by Linjiang Beifeng Diatomite Company, Jilin Province, (The mass fractions of main compositions included: $70.38 \% \mathrm{SiO}_{2}, 2.37 \% \mathrm{Al}_{2} \mathrm{O}_{3}, 1.42 \%$ $\mathrm{K}_{2} \mathrm{O}$, and $10.58 \% \mathrm{CaO}$ ). The pore-forming agent was carbon powder, provided by Nanjing Greifa Carbon Material Company; Bauxite powders ( 325 mesh), $\mathrm{Al}_{2} \mathrm{O}_{3} \geq 65 \%$, was produced by Yangquan Haotianwei Refractory Company; 
Quartz was purchased from the Xinhui Mining Processing Plant in Lingshou County, China, and feldspar was obtained from Yantai Yitao Mining Company. The aforementioned raw materials were industrially pure. The analytically pure sodium silicate was used as a dispersant obtained from Beijing Tongguang Fine Chemical Company, and the analytically pure hydroquinone was purchased from Qingdao Yousuo Chemical Technology Company.

\section{Sample Preparation and Characterization}

Diatomite, the pore-forming agent, sintering aid, water, and dispersant (a mass ratio of 82: 6: 18: 120: 2), were added to the ball mill with a grinding medium $\left(\mathrm{ZrO}_{2}\right.$ ceramic ball with $\varphi \approx 8 \mathrm{~mm}$ ) and ground for $20 \mathrm{~min}$. The materials were then put into an oven and dried at $105^{\circ} \mathrm{C}$. The diatomite-based porous ceramsite was obtained by dispersing, rolling, and calcining in a box resistance furnace at $1020^{\circ} \mathrm{C}$ for $2 \mathrm{~h}$.

A Japan JSM-6490LV SEM was employed to observe the micromorphology of the ceramsite. The pore size distribution of samples was detected using an American Auto Pore IV 9500 mercuryporosimeter. An ultraviolet-visible spectrophotometer produced by LAMBDA of PerkinElmer Company in the United States was used to detect the absorbance of hydroquinone wastewater at $288 \mathrm{~nm}$. The $\mathrm{pH}$ value of hydroquinone wastewater was measured with JY-pH $2.0 \mathrm{pH}$ agent (Shimazu, Japan). The porosity of diatomite-based porous ceramsite was determined using the Archimedes method.

\section{Adsorption Experiment}

In this experiment, $1 \mathrm{~g}$ of the diatomite-based porous ceramsite was placed into a $150 \mathrm{~mL}$ conical flask, and $50 \mathrm{~mL}$ of hydroquinone solution at a concentration of $50 \mathrm{mg} . \mathrm{L}^{-1}$ was added. The conical flask was sealed and placed into a constant temperature shaking table for shaking. The $\mathrm{pH}$ was adjusted to 2-9 with $0.1 \mathrm{~mol} . \mathrm{L}^{-1} \mathrm{HCl}$ or $\mathrm{NaOH}$ solution $\left(25^{\circ} \mathrm{C}, 120\right.$ r.min ${ }^{-1}, 24$ h). After the supernatant was filtered by a 0.45 $\mu \mathrm{m}$ membrane filter, its absorbance was measured to be 288 $\mathrm{nm}$ using an ultraviolet spectrophotometer. According to the Lambert-Beer law, if the absorbance of the maximum wavelength of a solution has a good linear relationship with the concentration of the solution, so the adsorption $q_{\mathrm{e}}$ and the removal rate $r$ of hydroquinone can be calculated from the absorbance.

$$
\begin{array}{r}
\mathrm{r}=\frac{\left(C_{0}-C e\right)}{C_{0}} \times 100 \% \\
\mathrm{q}_{\mathrm{e}}=\frac{V \times\left(C_{0}-C \mathrm{e}\right)}{\mathrm{m}}
\end{array}
$$

Where: $C_{0}$ is the concentration of hydroquinone before adsorption (mg. $\left.\mathrm{L}^{-1}\right) ; C_{\mathrm{e}}$ represents the concentration of hydroquinone at adsorption equilibrium $\left(\mathrm{mg} . \mathrm{L}^{-1}\right) ; m$ is the mass of adsorbent $(\mathrm{g})$; $V$ is the volume of solution (L).

\section{Establishment of Adsorption Kinetic, Adsorption Thermodynamic and Dynamic Boundary Models}

Adsorption kinetics, adsorption thermodynamic, and dynamic boundary models (Li et al. 2015, Jing et al. 2018, Zhu et al. 2016, Duan et al. 2011, Qu et al. 2018, Cheng et al. 2017, Chiara et al. 2019) of diatomite-based porous ceramsite to hydroquinone are listed in Tables 1-3 respectively.

\section{RESULTS AND DISCUSSION}

\section{Micromorphology of the Diatomite-based Porous Ceramsite}

Fig. 1 shows the SEM image of the diatomite-based porous ceramsite. The diatomite particles basically maintain the original pore structure (The small holes are distributed in the plate-shaped particles). Due to high-temperature calcination, the smaller holes on the diatomite particles disappear. The plate-shaped particles and tiny particles (sintering aids and pore-forming agents) are stacked to form a large gap. A large

Tables 1: Adsorption kinetics of diatomite-based porous ceramsite to hydroquinone.

\begin{tabular}{|ll|}
\hline Models & \multicolumn{1}{c|}{ Equations } \\
\hline Quasi-first-order kinetic model & $q_{t}=q_{e}\left(1-e^{-\kappa_{1} l}\right)$ \\
Quasi-second-order kinetic model & $q_{t}=\frac{k_{2} q_{e}{ }^{2} t}{\left(1+k_{2} q_{e} t\right)}$ \\
Elovich model & $q_{t}=a+k \ln t$ \\
Double-constant model & $q_{t}=e^{(a+k \ln t)}$ \\
\hline
\end{tabular}

Where $q_{t}\left(\mathrm{mg} \cdot \mathrm{g}^{-1}\right)$ is the adsorption capacity at the time of $t, q_{\mathrm{e}}\left(\mathrm{mg} \cdot \mathrm{g}^{-1}\right)$ is the adsorption capacity at equilibrium; $C_{\mathrm{e}}$ and $C_{t}\left(\mu \mathrm{mol} . \mathrm{L}^{-1}\right)$ represent the adsorption concentrations at equilibrium and $t$, respectively; $K$ and $k_{0}$ denote the adsorption rate constant and $a$ is the remaining constant. 
Tables 2: Adsorption thermodynamics of diatomite-based porous ceramsite to hydroquinone.

\begin{tabular}{|l|c|}
\hline Models & Equations \\
\hline Langmuir adsorption isotherm & $q_{e}=\frac{q_{m} k_{L} C_{e}}{1+k_{L} C_{e}}$ \\
Toth adsorption isotherm & $q_{e}=\frac{q_{m} C_{e}}{\left(k_{T h}+C^{t}\right)^{\frac{1}{t}}}$ \\
Redlich-Peterson adsorption isotherm & $q_{e}=\frac{A C_{e}}{1+B C_{e}^{g}}$ \\
Koble-Corrigan adsorption isotherm & $q_{e}=\frac{A C_{e}^{n} e_{e}}{1+B C^{n}{ }_{e}}$ \\
\hline
\end{tabular}

Where $q_{e}\left(\mathrm{mg} \cdot \mathrm{g}^{-1}\right)$ is the adsorption capacity at equilibrium, $q_{m}\left(\mathrm{mg} \cdot \mathrm{g}^{-1}\right)$ is the maximum adsorption capacity; $C e$ represents the concentration of adsorbate in the solution at equilibrium; $k_{L}$ is the Langmuir isotherm constant (related to the energy of adsorption); $k_{F}$ stands for the Freundlich isotherm constant (related to adsorption capacity and strength of adsorbents); $k_{T h}$ is the Toth isotherm constant.

Tables 3: Dynamic boundary model of diatomite-based porous ceramsite to hydroquinone.

\begin{tabular}{|ll|}
\hline Models & Equations \\
\hline Liquid film diffusion & $\ln (1-F)=-k_{\mathrm{t}}$ \\
Intragranular diffusion & $1-3(1-F)^{2 / 3}+2(1-F)=k_{\mathrm{t}}$ \\
Chemical reaction & $1-(1-F)^{1 / 3}=k_{\mathrm{t}}$ \\
\hline
\end{tabular}

Where, $F$ is the adsorption fraction at time $t, F=\mathrm{qt} / \mathrm{qe} ; k\left(\mathrm{~min}^{-1}\right)$ is the rate constant.

number of three-dimensional pores form an organic hole between the aggregated particles and the particles.

\section{Pore Structure Characteristics of the Diatomite-based Porous Ceramsite}

The pore diameter distribution curves of the diatomite-based porous ceramsite (Fig. 2) are mainly concentrated at 500 to $3,000 \mathrm{~nm}$. The results of the pore size distribution, porosity, and specific surface area of the diatomite-based porous ceramsite (before and after toner addition) by the mercury injection are displayed in Table 4. It can be seen, after adding

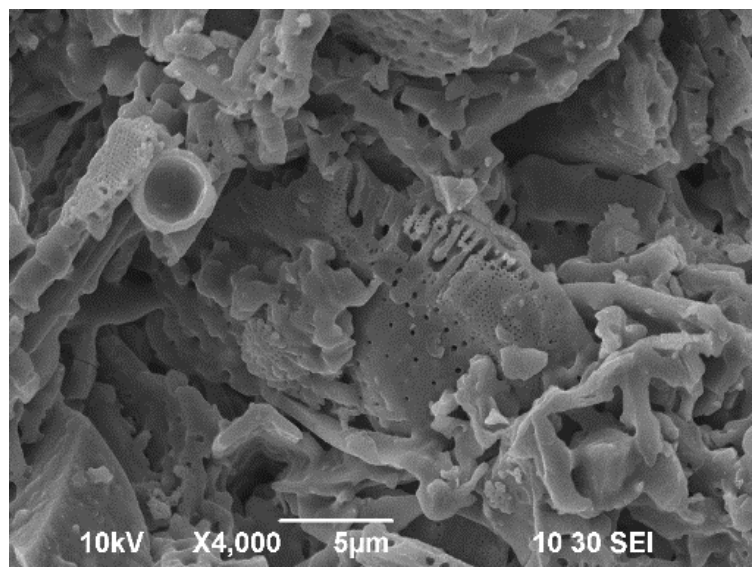

Fig. 1: SEM micrographs of the diatomite-based porous ceramsite. the toner, the pore size is widely distributed, the specific surface area is larger, and the porosity is higher. Thus the adsorption capacity of the material is greatly improved.

\section{Effect of pH on the Adsorption of Hydroquinone by the Diatomite-based Porous Ceramsite}

Fig. 3 illustrates the effect of $\mathrm{pH}$ on the adsorption of hydroquinone by the diatomite-based porous ceramsite. When the $\mathrm{pH}$ is in the range of 2-7, the adsorption capacity and removal rate of the hydroquinone by the diatomite-based porous

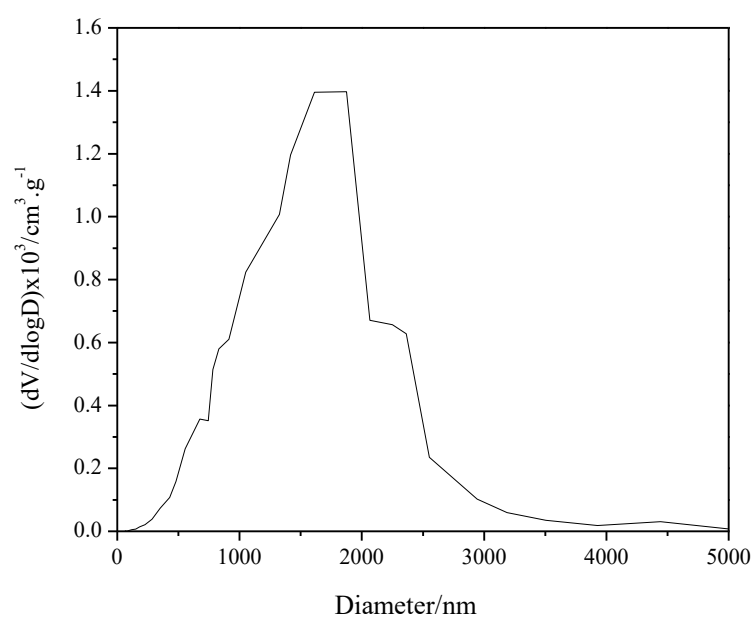

Fig. 2: Pore size distribution of the diatomite-based porous ceramsite. 
Table 4: Pore size distribution, porosity, and specific surface area of the diatomite-based porous ceramsite.

\begin{tabular}{|lllll|}
\hline Pore structure index & $\begin{array}{l}\text { Specific surface area } \\
\left(\mathrm{m}^{2} \cdot \mathrm{g}^{-1}\right)\end{array}$ & $\begin{array}{l}\text { Mean pore diameter } \\
(\mathrm{nm})\end{array}$ & $\begin{array}{l}\text { Pore size distribution } \\
(\mathrm{nm})\end{array}$ & $\begin{array}{l}\text { Porosity } \\
(\%)\end{array}$ \\
\hline No carbon powder & 3.21 & 723.4 & $460 \sim 1800$ & 23.7 \\
With carbon powder & 6.14 & 1493.8 & $500 \sim 3000$ & 47.8 \\
\hline
\end{tabular}

ceramsite increase with increasing $\mathrm{pH}$. When the $\mathrm{pH}$ is 7 , the removal effect is most efficient. The adsorption capacity and removal rates are $4.56 \mathrm{mg} \cdot \mathrm{g}^{-1}$ and $91.2 \%$, respectively. When the $\mathrm{pH}$ is greater than 7 , the adsorption capacity of the diatomite-based porous ceramsite to hydroquinone decreases significantly. This may be due to the degree of dissociation of hydroquinone being lower under acidic conditions. With an increase in $\mathrm{pH}$, the degree of dissociation of hydroquinone increases, which is conducive to adsorption. In the alkaline environment, the hydroxyl group of hydroquinone is further dissociated. The hydrogen bond between the hydroquinone and the solvent water takes up too many adsorption sites, which leads to a decrease in the removal rate of hydroquinone by the diatomite-based porous ceramsite. Therefore, the $\mathrm{pH}$ value of the solution was adjusted to 7 in subsequent experiments.

\section{Adsorption Kinetic Analysis}

According to the equations in Table 1, the non-linear kinetic adsorption models such as the quasi-first-order dynamic model, the quasi-second-order kinetic model, the Elovich model, and the double-constant model were respectively fitted. The non-linear kinetic adsorption of hydroquinone by the diatomite-based porous ceramsite is illustrated in Fig. 4, and the relevant parameters are shown in Table 5.

Fig. 4 shows that the adsorption process of hydroquinone

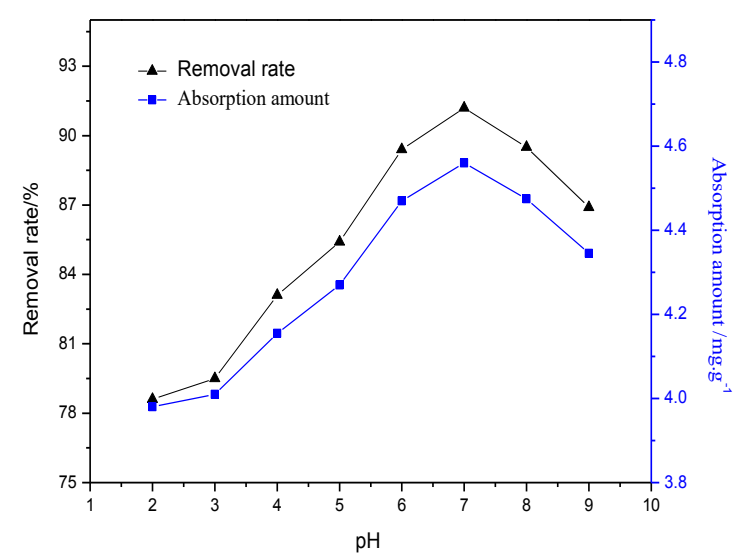

Fig. 3: Effect of $\mathrm{pH}$ on adsorption of the diatomite-based porous ceramsite. by the diatomite-based porous ceramsite occurs in two stages. The adsorption capacity increases rapidly in the range from 0 to $120 \mathrm{~min}$. When $t$ is $120 \mathrm{~min}$, the adsorption capacity reaches $4.35 \mathrm{mg} \cdot \mathrm{g}^{-1}$. After $120 \mathrm{~min}$, the adsorption capacity increases slowly and gradually become stable. Finally, at 1,440 min, the adsorption capacity reaches $4.4 \mathrm{mg} \cdot \mathrm{g}^{-1}$. This is because in the first stage, there is a large number of adsorption sites on the surface of ceramsite, and the adsorption amount increases rapidly. In the second stage, hydroquinone in the solution occupies a large number of adsorption sites on the surface of ceramsite, resulting in slow adsorption. According to Table 1, the correlation coefficient $\left(R^{2}=0.979\right)$ of the quasi-first-order kinetic equation is greater than that of the quasi-second-order kinetic equation $\left(R^{2}=0.953\right)$, the Elovich model, and the double constant.

The adsorption process of hydroquinone by the diatomite-based porous ceramsite can be accurately demonstrated by quasi-first-order and quasi-second-order kinetic equations. The quasi-first-order kinetic model is based on the assumption that the adsorption process is controlled by diffusion steps. The quasi-second-order kinetic model is based on the assumption that the adsorption rate is controlled by the chemical adsorption mechanism. The quasi-second-order kinetic model includes all adsorptions, such as liquid film diffusion, intraparticle diffusion, and chemical adsorption (Zhang et al. 2018, Pholosi et al. 2020). The adsorption of

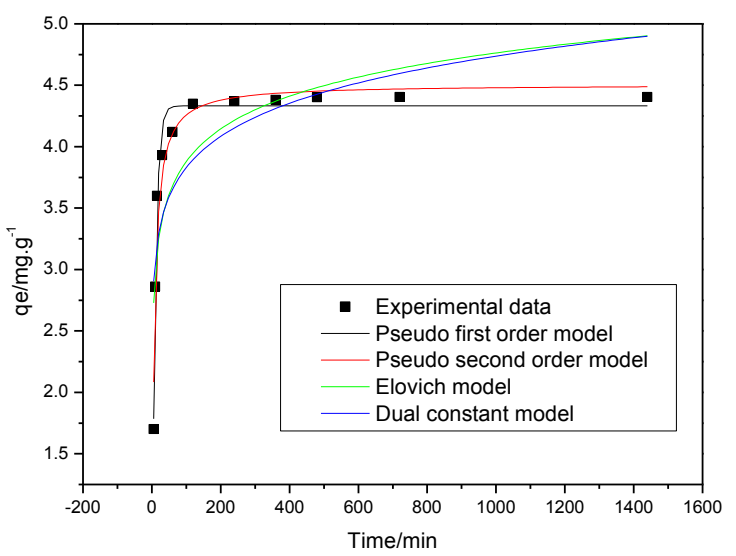

Fig. 4: Nonlinear dynamic fitting curve. 
hydroquinone by the diatomite-based porous ceramsite is dominated by liquid film diffusion. The quasi-first-order kinetic model can describe the whole adsorption process and is, therefore, more accurate in describing the adsorption process of hydroquinone by the diatomite-based porous ceramsite.

\section{Adsorption Thermodynamic Analysis}

The adsorption isotherm equations (Langmuir, Koble-Corrigan, Toth, and Redlich-Peterson) were used to fit the experimental data of the adsorption of hydroquinone by the diatomite-based porous ceramsite (Cui et al. 2019, Mudzielwana et al. 2019, Raganati et al. 2018, Lonappana et al. 2018, Wang et al. 2019b). The fitting results are shown in Fig. 5, and the fitting parameters are summarized in Table 6.
From Fig. 5 and Table 6, the Langmuir and Koble-Corrigan equations can well fit the data of the adsorption isotherm. The Langmuir equation is an adsorption isothermal model based on single molecular layers, that is, adsorption only occurs on the outer surface of the adsorbent. The Koble-Corrigan equation can be used to present the composite adsorption system of uniform adsorption and uneven adsorption, which shows that the adsorption process is more complex and related to the porous composite characteristics of ceramsite. The adsorption characteristics of diatomite-based porous ceramsite conform to the fixed-point adsorption of a single molecular layer. Each active adsorption site on the ceramsite only adsorbs one molecule, and there is no transfer or interaction between single molecules adsorbed on the site. The

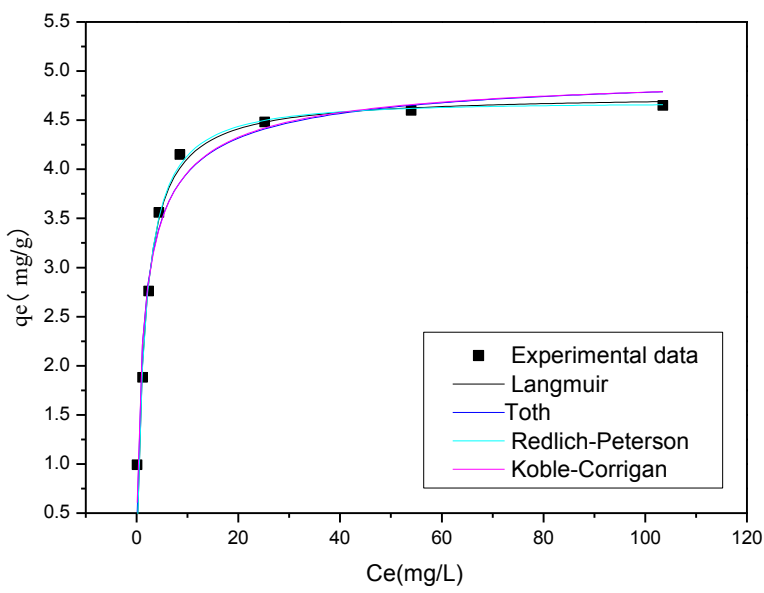

Fig. 5: Thermodynamic nonlinear fitting diagram.

Table 5: The fitting parameters of the kinetic adsorption model.

\begin{tabular}{|c|c|c|c|c|c|c|}
\hline Kinetic model & \multicolumn{3}{|c|}{ Pseudo-first-order model } & \multicolumn{3}{|c|}{ Pseudo-second-order model } \\
\hline HQ & $\begin{array}{c}R^{2} \\
0.979\end{array}$ & $\begin{array}{c}\mathrm{q} \\
4.33256\end{array}$ & $\begin{array}{c}\mathrm{k} \\
0.10615\end{array}$ & $\begin{array}{c}R^{2} \\
0.953\end{array}$ & $\begin{array}{c}Q \\
4.50573\end{array}$ & $\begin{array}{c}K \\
0.03816\end{array}$ \\
\hline Kinetic model & \multicolumn{3}{|c|}{ Elovich model } & \multicolumn{3}{|c|}{ Double-constant model } \\
\hline HQ & $\begin{array}{c}R^{2} \\
0.669\end{array}$ & $\begin{array}{c}a \\
2.10892\end{array}$ & $\begin{array}{c}k \\
0.38423\end{array}$ & $\begin{array}{c}R^{2} \\
0.603\end{array}$ & $\begin{array}{c}a \\
0.91768\end{array}$ & $\begin{array}{c}k \\
0.09233\end{array}$ \\
\hline
\end{tabular}

Table 6: Fitting parameters of the thermodynamic model of adsorption.

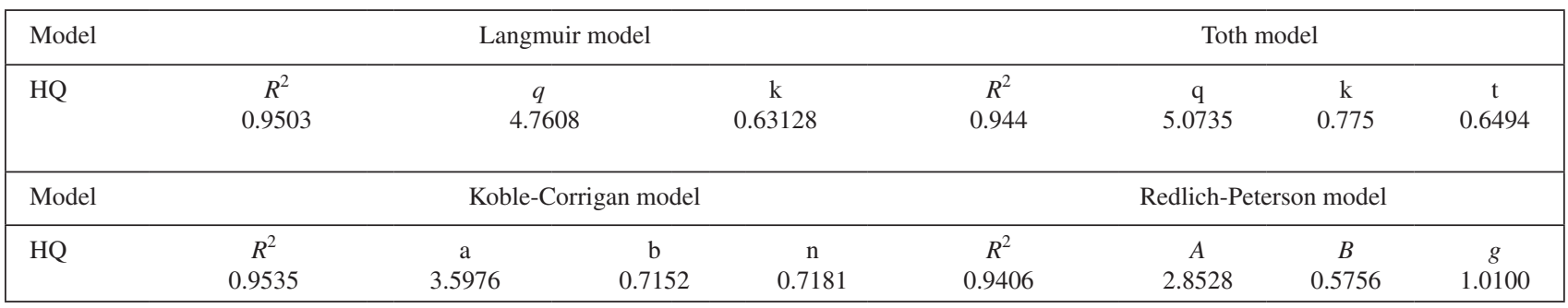


maximum adsorption capacity is a fixed value. Meanwhile, the adsorption on the surface of ceramsite is heterogeneous and belongs to a heterogeneous composite adsorption system.

\section{Dynamic Boundary Analysis}

A Dynamic boundary model can be used to describe the adsorption behavior of porous adsorbents. The adsorption process on the surface of the diatomite-based porous ceramsite is divided into three steps: 1) liquid film diffusion, 2) intragranular diffusion, 3) adsorption chemical reaction on the active groups inside the particles. According to Table 1, the linear fitting of the dynamic boundary model is shown in Fig. 6, and the fitting parameters are summarized in Table 7.

From the fitting parameters in Table 7 , the liquid film diffusion model exhibits a higher fitting degree for

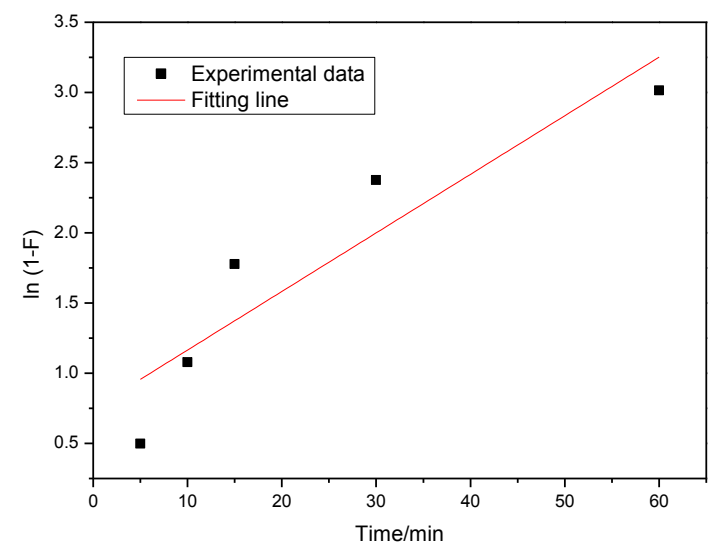

the adsorption of hydroquinone by the diatomite-based porous ceramsite with a correlation coefficient $R^{2}=0.848$, followed by the fitting degrees of the internal diffusion model of particles, and the chemical reaction model, which indicated that the adsorption rate of hydroquinone on the surface of ceramsite is mainly controlled by the liquid film diffusion (Hosokawa et al. 2018, Sun et al. 2017). This data demonstrated that the adsorption mechanism of hydroquinone by diatomite-based porous ceramsite is mainly through micropores on the ceramsite surface and the charge adsorption on the material surface (Jegasothya et al. 2004, Sun et al. 2018, Li et al. 2018). The $K$ value can be used to measure the speed of adsorption. The $K$ value of the liquid film diffusion model is 0.04173 , which is much larger than that fitted by the intragranular diffusion and chemical

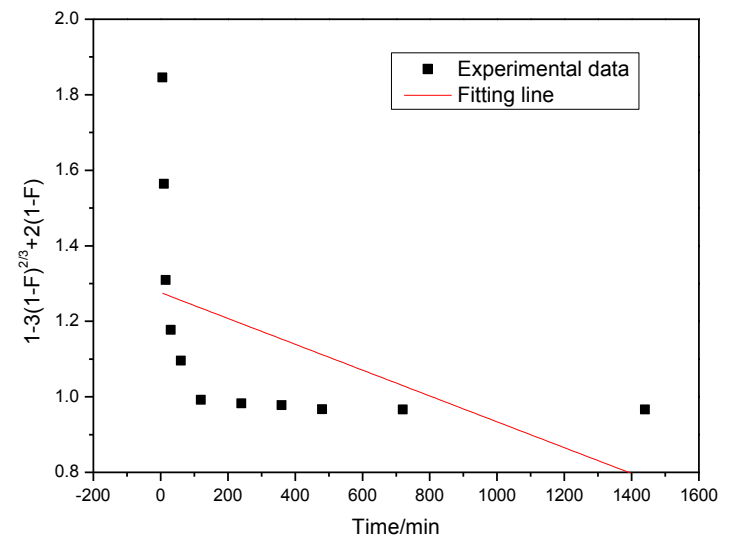

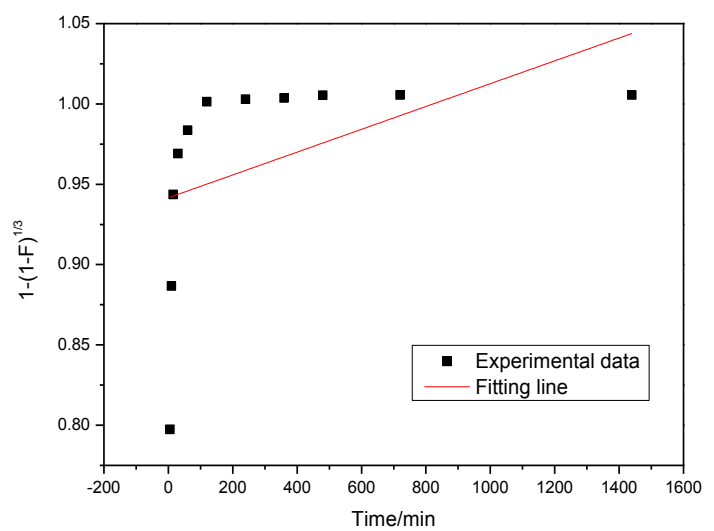

Fig. 6: The fitting lines of dynamic boundary models on the diatomite-based porous ceramsite.

Table 7: The fitting result of the dynamic boundary model.

\begin{tabular}{|c|c|c|c|}
\hline Fitting parameters & Liquid film diffusion & $\begin{array}{l}\text { Intragranular } \\
\text { diffusion }\end{array}$ & Chemical reaction \\
\hline$k$ & 0.04173 & 0.00193 & 0.00164 \\
\hline$R^{2}$ & 0.84775 & 0.17884 & 0.13333 \\
\hline
\end{tabular}


reaction models. These results indicated that the liquid film diffusion is relatively rapid in the adsorption process, while the intragranular diffusion and chemical reactions are relatively slow in the adsorption process.

\section{CONCLUSION}

Diatomite-based porous ceramsite has a high porosity, a specific surface area, and a better adsorption performance for hydroquinone. When the $\mathrm{pH}$ is 7 , the removal rate and adsorption capacity of hydroquinone in the sample can reach $91.2 \%$ and $4.56 \mathrm{mg}^{-\mathrm{g}^{-1}}$, respectively. The quasi-first-order kinetic, and the quasi-second-order kinetic equations have a high fitting degree for the adsorption data of the diatomite-based porous ceramsite. The diffusion of the liquid films dominates the adsorption process of hydroquinone by ceramsite and the quasi-first-order kinetic equation is more accurate. The Langmuir and Koble-Corrigan equations can well fit the adsorption isotherm data. The adsorption characteristics of the diatomite-based porous ceramsite conform to the fixed-point adsorption of a single molecular layer. The adsorption on the surface of ceramsite is heterogeneous and seen as a heterogeneous composite adsorption system. The fitting results of the dynamic boundary model and the experimental data indicated that the liquid film diffusion model has a high fitting degree for the adsorption process of hydroquinone by the diatomite-based porous ceramsite, with a correlation coefficient of $R^{2}=0.848$ and adsorption rate of $k=0.04173$. The adsorption mechanism of hydroquinone by the diatomite-based porous ceramsite mainly occurs in the micropores on the ceramsite surface, and the charge adsorption on the material surface.

\section{ACKNOWLEDGEMENTS}

This work was financially supported by the National Natural Science Foundation of China (Grant no. 51378205), the Science and Technology Department, Henan Province (Grant no. 182102311080), and a Special project of geological and mineral evaluation of China Geological Survey (Grant no. YMZB-2017014F).

\section{REFERENCES}

Che, T.K., Pan, B.F. and Jian, O.Y. 2018. The laboratory evaluation of incorporating ceramsite into HMA as fine aggregates. Constr. Build Mater., 186: 1239-1246.

Chen, Y.C., Shi, J.W., Rong, H., Zhou, X., Chen, F.Y., Li, X.L., Wang, T. and Hou, H.B. 2010. Adsorption mechanism of lead ions on porous ceramsite prepared by co-combustion ash of sewage sludge and biomass. Sci. Total Environ., 702: 135017.

Cheng, S., Zhang, L.B., Xia, H.Y., Peng, J.H., Shu, J.H., Li, C.Y., Jiang, X. and Zhang, Q. 2017. Adsorption behavior of methylene blue onto wasted rived adsorbent and exhaust gases recycling. RSC Adv., 7: 27331-27341.
Chiara, G., Panayiotis, T., Chanan, E., Rachel, P., David, A.D., Tod, P., David, P., Georg, H. and Angelos, M. 2019. Adsorption behavior of organic molecules: a study of benzotriazole on $\mathrm{Cu}$ (111) with spectroscopic and theoretical methods. Langmuir, 35(4): 882-893.

Cui, Z.X., Gan, J.Z., Xue, Y.Q., Zhang, J., Zhang, R., Liu, J.Y. and Hao, J. 2019. Adsorption selectivity of cubic nano- $\mathrm{CeO}_{2}$ and effect of particle size on adsorption thermodynamics. Fluid Phase Equilib., 502: 112277.

Duan, L.H., Guo, Y.S. and Yang, J.Q. 2011. Study on the effect of a magnetic field on $\mathrm{Pb}$ (II) removal using modified chitosan. Adv. Chem. Eng. Sci., 2: 101-107.

Ergürhan, O., Parlak, C., Alver, O. and Senyel, M. 2018. Conformational and electronic properties of hydroquinone adsorption on $\mathrm{C}_{60}$ fullerenes: Doping atom, solvent, and basis set effects. J. Mol. Struct., 1167: 227-231.

Font, A., Soriano, L., Reig, L., Tashima, M., Borrachero, M.V., Monzó, J. and Payá, J. 2018. Use of residual diatomaceous earth as a silica source in geopolymer production. Mater. Lett., 223: 10-13.

Hosokawa, S., Hayashi, K. and Tomiyama, A. 2018. Evaluation of adsorption of surfactant at a moving interface of a single spherical drop. Exp. Therm. Fluid Sci., 96: 397-405.

Iuchaurroudo, N., Font, J., Ramos, C. P. and Haure, P. 2016. Natural diatomites: Efficient green catalyst for Fenton-like oxidation of orange . Appl. Catal. B: Environ., 181: 481-494.

Jegasothya, S., Slatera, N.K.H., Deneckerb, C., Sherringtonb, D.C., Leic, Z. and Sutherland, A.J. 2004. Kinetics of oxidation of hydroquinone by polymer-supported hypervalent iodine oxidant, iodoxybenzoic acid. Chem. Eng. J., 105: 1-10.

Jing, Q.X., Wang, Y.Y., Chai, L.Y., Tang, C.J., Huang, X.D., Guo, H., Wang, W. and You, W. 2018. Adsorption of copper ions on porous ceramsite prepared by diatomite and tungsten residue. Trans. Nonferrous Met. Soc. China, 28: 1053-1060.

Li, G. T., Feng, Y. M. and Chai, X. Q. 2015. Equilibrium and thermodynamic studies for adsorption of 1, 4- Benzoquinone by fly ash. Nat. Environ. Pollut. Technol., 14: 865-869.

Li, L. L., Fan, L. L., Sun, M., Qiu, H. M., Li, X. G., Duan, H. M. and Luo, C. N. 2013. Adsorbent for hydroquinone removal based on graphene oxide functionalized with magnetic cyclodextrin-chitosan. Int. J. Biological Macromolecules, 58: 169-175.

Li, T. T., Liu, Y. M., Wang, T., Wu, Y. L. and He, Y. L. Yang, R. and Zheng, S. R. 2018. Regulation of the surface area and surface charge property of MOFs by multivariate strategy: Synthesis, characterization, selective dye adsorption, and separation. Micropor. Mesopor. Mat., 272: 101-108.

Li, X., Shi, X.S., Yang, Z.M., Xu, X.H. and Guo, R.B. 2019. Effects of recyclable ceramsite as the porous bulking agent during the continuous thermophilic composting of dairy manure. J. Cleaner Prod., 217: 344-351.

Lonappana, L., Rouissia, T., Brara, S.K., Vermab, M. and Surampallic, R.Y. 2018. An insight into the adsorption of diclofenac on different biochars: Mechanisms, surface chemistry, and thermodynamics. Bioresour. Technol., 249: 386-394.

Mudzielwana, R., Gitari, M.W. and Ndungu, P. 2019. Performance evaluation of surfactant modified kaolin clay in As(III) and As(V) adsorption from groundwater: adsorption kinetics, isotherms, and thermodynamics. Heliyon, 5: e02756.

Pholosi, A., Naidoo, E.B. and Ofomaja, A.E. 2020. Intraparticle diffusion of $\mathrm{Cr}(\mathrm{VI})$ through biomass and magnetite coated biomass: A comparative kinetic and diffusion study. S. Afr. J. Chem. Eng., 32: 39-55.

Podder, M.S. and Majumder, C.B. 2016. Sequestering of As(III) and As(V) from wastewater using a novel Neem leaves/ $\mathrm{MnFe}_{2} \mathrm{O}_{4}$ composite biosorbent. Int. J. Phytoremediat., 18: 1237-1257.

Qin, J., Cui, C., Cui, X. Y., Hussain, A. and Yang, C. M. 2015. Preparation and characterization of ceramsite from lime mud and coal fly ash. Constr. Build Mater., 95: 10-17. 
Qu, J.L., Li, Q., Luo, C., Cheng, J. and Hou, X.M. 2018. Characterization of flake boron nitride prepared from the low-temperature combustion synthesized precursor and its application for dye adsorption. Coatings, $8(6): 214$

Raganati, F., Alfe, M., Gargiulo, V., Chirone, R. and Ammendola, P. 2018. Isotherms and thermodynamics of $\mathrm{CO}_{2}$ adsorption on a novel carbon-magnetite composite sorbent. Chem. Eng. Research. Des., 134: 540-552.

Sun, S., Chen, L.Y., Sun, H.L. and Zha, T.Y. 2018. Adsorption and charge transfer of lithium at electrified graphene/electrolyte interface. Electrochim. Acta., 259: 1089-1094.

Sun, X.L., Wang, Z.G. and Fu, Y.Q. 2017. Adsorption and diffusion of sodium on graphene with grain boundaries. Carbon, 116: 415-421.

Tan, G.Q., Wu, Y., Liu, Y. and Xi, D. 2018. Removal of Pb(II) ions from aqueous solution by manganese oxide coated rice straw biochar - A lowcost and highly effective sorbent. J. Taiwan Inst. Chem. Eng., 84: 85-92.

Wang, H.Y., Wang, B.D., Li, J.H. and Zhu, T.L. 2019. Adsorption equilibrium and thermodynamics of acetaldehyde/acetone on activated carbon. Sep. Purif. Technol., 209, 535-541.

Wang, X.K., Zheng, G.D., Chen, T.B., Nie, E. Q., Wang, Y.W., Shi, X.X. and Liu, J.W. 2019. Application of ceramsite and activated alumina balls as recyclable bulking agents for sludge composting. Chemosphere, 218: 42-51.
Wu, H. M., Fan, J.L., Zhang, J., Ngo, H.H., Guo, W. S., Liang, S., Lv, J.L., Lu, S.Y., Wu, W.Z. and Wu, S.Q. 2016. Intensified organics and nitrogen removal in the intermittent-aerated constructed wetland using a novel sludge-ceramsite as substrate. Bioresour. Technol., 210: 101-107.

Xu, C., Jiang, L., Qin, X L., Jin, C., Liu, L.J., Yu, S. and Xian, M. 2019. Enhancement mechanism behind the different adsorptive behaviors of nitro/amine modified hyper crosslinked resins towards phenols. J. Taiwan Inst. Chem. Eng., 102: 340-348.

Yıldız, N., Gönülşen, R., Koyuncu, H. and Çalımlı, A. 2005. Adsorption of benzoic acid and hydroquinone by organically modified bentonites. Colloids Surf. A: Physicochem. Eng. Aspects, 260: 87-94.

Zahra, A., Jamshid, E.L., Jamil, K. and Robab, H.L. 2018. Properties of sustainable cement mortars containing a high volume of raw diatomite. Sust. Mater. Technol., 16: 47-53.

Zhang, L.K., Liu, X.Y., Wang, W.D., Li, Y.M., Sun, P., Shang, S.P. and Jiang, Q.H. 2018. Characteristics and mechanism of lead adsorption from aqueous solutions by oil crops straw-derived biochar. Trans. Chin. Soc. Agric. Eng., 34: 218-226.

Zhu, J., Wang, P., Lei, M.J., Zhang, W.L. and Chen, Y. 2016. Composite modification of diatomite and its adsorption characteristic of $\mathrm{Cd}^{2+}$ in aqueous solutions. Acta Sci. Circum., 36: 2059-2066. 